\title{
Association of IFITM3 rs12252 polymorphisms, BMl, diabetes, and hypercholesterolemia with mild flu in an Iranian population
}

Parvaneh Mehrbod ${ }^{1}$, Sana Eybpoosh ${ }^{2}$, Fatemeh Fotouhi ${ }^{1}$, Hadiseh Shokouhi Targhi $^{1}$, Vahideh Mazaheri ${ }^{1}$ and Behrokh Farahmand ${ }^{1 *}$

\begin{abstract}
Background: IFITM3 has been suggested to be associated with infection in some ethnic groups. Diabetes and hypercholesterolemia are also important clinical conditions that can predispose individuals to infection. The aim of this study was to investigate the association of rs 12252 C polymorphism, BMl, diabetes, and hypercholesterolemia with mild flu in an Iranian population.
\end{abstract}

Methods: We conducted a case-control study, including 79 mild flu and 125 flu-negative individuals attending primary care centers of three provinces of Iran (i.e, Markazi, Semnan, and Zanjan). Pharyngeal swab specimens were collected from all participants, and were subjected to RNA and DNA extractions for Real-time PCR and PCR tests. All PCR products were then sequenced to find T/C polymorphisms in the rs12252 region. Data on demographic, anthropometric, and clinical variables were collected from participants' medical records available in the primary care centers. The data was analyzed using DNASIS (v. 2.5) and Stata (v.11) software.

Results: All participants were of Fars ethnic background. The allele frequency for rs $12252-C$ was found to be 9.49\% among cases and 2.40\% among controls. Carriers of the rs 12252 C allele (CT + CC genotypes) showed 5.92 folds increase in the risk of mild flu comparing to the T allele homozygotes ( $P$ value: 0.007 ). We also found a significant positive association between rs12252 C allele heterozygote and mild flu (OR: 7.62, $P$ value: 0.008), but not in $C$ allele homozygote group (OR: 2.71, $P$ value: 0.406$)$. Similarly, we did not find a significant association between mild flu and BMI (OR: 1.06, $P$ value: 0.087 ), diabetes (OR: 0.61, $P$ value: 0.392 ), and hypercholesterolemia (OR: 0.50, $P$ value: 0.393 ) in multivariable logistic regression.

Conclusions: This is the first study evaluating the association between rs12252 polymorphisms, diabetes, hypercholesterolemia, and BMI and susceptibility to mild flu in an Iranian population. Our results suggest a significant positive association between mild flu and rs12252 C allele heterozygous and carriage. Future replication of the strong association observed here between rs12252 C allele carriage and mild flu might candidate this polymorphism as a genetic marker for early screening of susceptibility to mild flu. Lack of significant association between C allele homozygous and mild flu, observed in this study, might be the result of small sample size in this group.

Trial registration: IR.PII.REC.1395.3.

Keywords: Human influenza, IFITM3 protein, Body mass index, Hypercholesterolemia, Diabetes, Polymorphism, Iran

\footnotetext{
*Correspondence: b_farahmand@pasteur.ac.ir

${ }^{1}$ Influenza and Other Respiratory Viruses Department, Pasteur Institute of Iran,

Tehran, Iran

Full list of author information is available at the end of the article
} 


\section{Background}

Influenza is the result of both host and viral genetic components combination. The viral genetic determinants and host immunity have been widely considered, while the host genetic determinants remain elusive [13]. The study of the host genetic factors involved in susceptibility to influenza is a promising strategy that may identify potential therapeutic targets [18]. As a result, systematic investigation of the association between host genetic factors and the occurrence of influenza is of pivotal importance. In 2009, the World Health Organization (WHO) identified as priority the studies which considered the role of host genetic factors on susceptibility to severe flu [17].

During viral infection, viral proteins and viral nucleic acids are detected by pathogen recognition receptors (PRRs). These recognition patterns activate signaling transduction pathways that trigger production of type I interferon and other related cytokines $[3,25]$. Type I interferon then elevates the expression of hundreds of genes, named interferon stimulated genes (ISGs), that weaken virus replication by a variety of mechanisms $[3,25]$.

It has been suggested that the expression of interferoninducible transmembrane (IFITM) genes restrict the replication of several highly pathogenic human viruses, especially those that enter the cell via acidic endosome $[3,10,26]$. These viruses include severe acute respiratory syndrome (SARS), coronavirus, Marburg and Ebola viruses, influenza A viruses (IAVs), dengue virus, and HIV-1 [2, 3, 5, 14, 20].

In humans, it has been predicted that rare SNP rs12252-C allele of IFITM3 produces an alternatively spliced transcript that encodes a truncated protein ( $\Delta 21$ IFITM3) leading to reduced control of virus replication in vitro. However, expression at mRNA or protein level of the $\Delta 21$ IFITM3 variant has not been detected to date $[7,9]$.

The value of IFITM3 in influenza virus infection was determined by Everitt et al. who showed that severity of influenza virus infection was greatly increased in IFITM3 knockout mice compared to the wild-type animals [9]. Everitt et al. and Zhang et al. demonstrated increased morbidity and mortality in rs12252-C homozygotes during the $\mathrm{H} 1 \mathrm{~N} 1$ influenza pandemic. Due to the high frequency of the rs12252-C allele in Asians, the effect of the homozygosity for this allele was proposed to translate to a population-attributable risk of $54.3 \%$ for severe flu in the Chinese population compared with $5.4 \%$ in Northern Europeans. Both studies were performed with small sample sizes of H1N1-infected patients, calling for further studies on large sample sizes. Two studies reported a strong association between IFITM3 SNP rs12252-C and worse clinical outcomes in patients infected with 2009 IAV pandemic. The studies, however, doubt the presence of such association, at least among
Europeans, as several rs-12,252-C homozygous patients only developed a mild flu $[9,31]$.

It appears that IFITM3 inhibits an early event after endocytosis of virion particles, by blocking virus release into the cytosol $[1,10,28]$. IFITM3 protein is considered to be the most active against IAV and resides in the late endosomes and lysosomes using several orthologous genetic approaches $[3,14]$. Wang and colleagues showed that inflammatory immune responses linked to the $\mathrm{C} / \mathrm{C}$ IFITM3 genotype during H7N9 infection play an important role in the pathogenesis of influenza. They found that patients with rs12252-C/C IFN-IFITM3 genotype had more rapid disease progression, and were less likely to survive [27].

Although previous studies concluded that the rs12252$\mathrm{C}$ variant leads to reduced control of virus replication in vitro, posterior studies did not find such effects. For example, Mills et al. found an association between rs12252 rare allele $\mathrm{C} / \mathrm{C}$ homozygotes and susceptibility to mild flu but they could not confirm previous reports for the association between this polymorphism and susceptibility to severe H1N1 infection [22]. The data obtained by López-Rodríguez et al. did not either suggest any role of rs12252-C in the development of severe IAV in their studied population. They suggested these groups might be at risk of severe influenza, hence individualized measures in the case of IAV is required [19].

Giao et al. also showed that except H1N1 influenza (pdm09), the risk of hospitalization due to other respiratory infections was higher among rs12252 C allele carriers comparing to patients with TT genotype [11].

It has been reported that local accumulation of cholesterol to the plasma membrane is important for clustering of viral structural proteins in lipid rafts to help assemble the virus particles [1]. Thus, the imbalance in cholesterol level may play a role in the susceptibility to influenza. The IFITM3 gene mutation may lead to an increase in impaired cholesterol levels [1]. As an instance, mutation rate of IFITM3 gene is shown to be high among Han Chinese population. Coronary artery disease and ischemic stroke are highly associated with BMI and serum cholesterol levels, and are the leading causes of morbidity and mortality in Han Chinese population [8, 12, 23]. Therefore, we performed this study to identify the association between mild flu and IFITM3 rs12252-C polymorphism, BMI, diabetes and hypercholesterolemia.

\section{Methods}

\section{Ethics statement}

Written informed consent was obtained from all participants. All procedures performed in this study involving human participants were according to the principles Helsinki declaration. The research protocol was approved 
by the Ethics Committee of Pasteur Institute of Iran (Ethics code: IR.PII.REC.1395.3).

\section{Participants}

We performed a case-control study on the samples collected from March 2015 to December 2015 in three provinces of northern-central Iran, including Markazi, Semnan, and Zanjan. Cases would be included in this study if they had apparent symptoms of respiratory tract infection, and were confirmed as mild flu with PCR test. Controls were flu-negative individuals based on the PCR results, and would be included in the study if they had no history of influenza. Both cases and controls should be based and currently residing in Markazi, Semnan, or Zanjan provinces. Having respiratory comorbidities, consumption of immune suppressive drugs, and previous vaccination against influenza virus were our exclusion criteria.

\section{Sample collection}

Demographic and anthropometric characteristics measured for each participant included participants' age (in years), province (Markazi, Semnan, and Zanjan provinces), Body Mass Index (BMI, $\mathrm{kg} / \mathrm{m}^{2}$ ), diabetes (Yes/No), hypercholesterolemia (Yes/No), and genotype in the IFITM3 rs12252 locus. The BMI of each participant was calculated using the formula: BMI $=[$ weight $(\mathrm{kg})] /[\text { height }(\mathrm{m})]^{2}$. The diabetes and hypercholesterolemia positive and negative cases were confirmed based on the patients' history reports. To test for influenza, pharyngeal specimen from each individual was obtained with a Dacron swab. Specimens were collected on dry ice in transport media containing Pen/Strep and Amphotericin B, and then were transferred to Pasteur Institute of Iran for determination of IAV. All samples were stored at $4{ }^{\circ} \mathrm{C}$ for $24 \mathrm{~h}$. Following vortex, swabs were discarded and the supernatants were aliquoted in sterile labeled micro-tubes and stored at $-80{ }^{\circ} \mathrm{C}$ for further testing.

\section{Detecting IAV in swab samples \\ Viral RNA extraction}

For each sample, viral RNA was extracted from $200 \mu \mathrm{l}$ fluid specimen using High Pure Viral RNA Kit, according to the manufacturer's instructions (Roche, Switzerland). The extracted RNA was isolated and resuspended in $50 \mu \mathrm{l}$ Elution Buffer and stored at $-80{ }^{\circ} \mathrm{C}$ for Real-time PCR assay.

\section{Primers and probes design}

In quantitative real-time PCR (qRT-PCR), primers and probes were designed and synthesized by SinaClon Co. (Iran) based on the latest WHO guideline. Table 1 describes the primers used for amplification of viral genes and RNaseP as housekeeping control.
Table 1 Real-time PCR Primers and probes specifications

\begin{tabular}{|c|c|c|}
\hline $\begin{array}{l}\text { Primers/ } \\
\text { Probes }\end{array}$ & Sequence $\left(5^{\prime}>3^{\prime}\right)$ & $\begin{array}{l}\text { Working } \\
\text { Concentration }\end{array}$ \\
\hline $\begin{array}{l}\text { InfA } \\
\text { Forward }\end{array}$ & GAC CRA TCC TGT CAC CTC TGA C & $40 \mu \mathrm{M}$ \\
\hline $\begin{array}{l}\text { InfA } \\
\text { Reverse }\end{array}$ & GCA TTY TGG ACA AAK CGT CTA & $40 \mu \mathrm{M}$ \\
\hline $\begin{array}{l}\text { InfA } \\
\text { Probe }^{a}\end{array}$ & TGC AGT CCT CGC TCA CTG GGC ACG & $10 \mu \mathrm{M}$ \\
\hline $\begin{array}{l}\text { SW InfA } \\
\text { Forward }\end{array}$ & GCA CGG TCA GCA CTT ATY CTR AG & $40 \mu \mathrm{M}$ \\
\hline $\begin{array}{l}\text { SW InfA } \\
\text { Reverse }\end{array}$ & GTG RGC TGG GTT TTC ATT TGG TC & $40 \mu \mathrm{M}$ \\
\hline $\begin{array}{l}S W \operatorname{InfA} \\
\text { Probe }\end{array}$ & $\begin{array}{l}\text { CYA CTG CAA GCC CA"T" ACA CAC AAG } \\
\text { CAG GCA }\end{array}$ & $10 \mu \mathrm{M}$ \\
\hline $\begin{array}{l}\text { Flu B } \\
\text { Primer }^{\mathrm{a}} \mathrm{M}\end{array}$ & GAGACACAATTGCCTACCTGCTT & $10 \mathrm{pm}$ \\
\hline $\begin{array}{l}\text { Flu B } \\
\text { Primer } \mathrm{M}\end{array}$ & TTCTTTCCCACCGAACCAAC & $10 \mathrm{pm}$ \\
\hline B Probe M & AGAAGATGGAGAAGGCAAAGCAGAACTAGC & $5 \mathrm{pm}$ \\
\hline $\begin{array}{l}\text { Rnase P } \\
\text { Forward }\end{array}$ & AGATTTGGACCTGCGAGCG & $40 \mu \mathrm{M}$ \\
\hline $\begin{array}{l}\text { Rnase P } \\
\text { Reverse }\end{array}$ & GAGCGGCTGTCTCCACAAGT & $40 \mu \mathrm{M}$ \\
\hline $\begin{array}{l}\text { Rnase P } \\
\text { Probe }^{a}\end{array}$ & TTCTGACCTGAAGGCTCTGCGCG & $10 \mu \mathrm{M}$ \\
\hline
\end{tabular}

TaqMan probes are labeled at 5'- end with the reporter molecule 6carboxyfluorescein (FAM) and with the quencher Blackhole Quencher 1 (BHQ1) at the 3'- end

'TaqMan probes are labeled at 5'- end with the reporter molecule 6carboxyfluorescein (FAM) and quenched internally at a modified " $\mathrm{T}$ " residue with BHQ1 with a modified 3'- end to prevent probe extension by Taq polymerase

\section{One-step quantitative real-time $P C R$}

Real-time PCR reactions were performed in total volume of $20 \mu \mathrm{l}$, using Rotor-Gene Q (QIAGEN). The reaction mixture consisted of 2X Master Mix, SuperScript ${ }^{\mathrm{III}} \mathrm{RT} /$ Platinum Taq Mix, specific primers and fluorescent probes. The thermal cycling program was followed based on WHO guideline. Briefly, reverse transcription was carried out at $50{ }^{\circ} \mathrm{C}$ for $30 \mathrm{~min}$, followed by $95^{\circ}$ for $2 \mathrm{~min}$ Taq inhibitor activation, and amplification at $95^{\circ}$ $\mathrm{C}$ for $15 \mathrm{~s}$ followed by $55^{\circ} \mathrm{C}$ for $30 \mathrm{~s}$.

\section{Genotyping of human IFITM3 rs12252 Human DNA extraction}

For each sample, genomic DNA was extracted from $100 \mu \mathrm{l}$ fluid specimen using $\mathrm{DNP}^{\mathrm{Tu}}$. High yield DNA Purification Kit, according to the manufacturer's instructions (Cinnagen, Iran). Briefly, $400 \mu \mathrm{l}$ of Lysis Solution was added to each sample. Following vortex and addition of precipitation solution, a second round vortex was performed. The samples were then centrifuged. Wash buffer was used for two times to wash the precipitation. Finally, solvent buffer was added and the tubes 
were warmed at $65{ }^{\circ} \mathrm{C}$ for $5 \mathrm{~min}$. The supernatant, which was the purified DNA, was stored at $-20{ }^{\circ} \mathrm{C}$ for PCR assay.

\section{Primers design}

Primers for PCR were designed and synthesized by SinaClon Co. (Iran) based on previous published articles [31]. The primers used for the amplification of human IFITM3 rs12252 were as follow: IFITM3-F 5' -GG AAACTGTTGAGAAACCGAA-3' and IFITM3-R 5'CATACGCACCTTCACGGAGT-3' to produce 351 bp PCR product. The18 S rRNA was amplified as internal housekeeping using theses primers sequences: $18 \mathrm{~S}-\mathrm{F}$ 5'-GGCCCTGTAATTGGAATGAGTC-3' and 18 S-R5'CCAAGATCCAACTACGAGCTT-3' to produce $145 \mathrm{bp}$ PCR product.

\section{Conventional PCR}

PCR reaction was performed in total volume of $25 \mu \mathrm{l}$, using Thermocycler (Germany). The reaction mixture consisted of Taq DNA Polymerase $2 \times$ Master Mix RED with $1.5 \mathrm{mM} \mathrm{MgCl}_{2}$ (Amplicon, Denmark), specific primers and DNase-free water. Amplification was carried out at $95^{\circ} \mathrm{C}$ for $30 \mathrm{~s}$ in order to pre-denature the template DNA, followed by 40 cycles of denaturation at $95^{\circ} \mathrm{C}$ for $30 \mathrm{~s}$, annealing at $60{ }^{\circ} \mathrm{C}$ for $1 \mathrm{~min}$ and extension at $72{ }^{\circ} \mathrm{C}$ for $1 \mathrm{~min}$. The final extension was completed at $72{ }^{\circ} \mathrm{C}$ for $5 \mathrm{~min}$. The PCR products were purified using PCR purification kit (Millipore), and subjected to sequencing (First Base Co, Malaysia) using the BigDye ${ }^{\bullet}$ Terminator v3.1 cycle sequencing kit chemistry. Then they were loaded into DNA Analyzer (GATC Biotech). Both sense and antisense strands of PCR products were directly sequenced using the same primers as the PCR amplification. SNPs were detected by direct sequence analysis using DNAsis MAX.3 software. The reference sequence for the IFITM3 gene was based on the sequence of human chromosome 11, clone GRCh38.p2.

\section{Genetic and statistical analysis}

Hardy-Weinberg equilibrium (HWE) was tested in cases and controls using the web tool developed by Rodriguez, and colleagues [24]. Using this tool, allele frequency and genotype distribution were calculated for cases and controls, as well. Statistical analyses were performed using Stata software (version 11). Continuous and categorical data were described in the usual fashion; means \pm SDs were used to describe continuous variables, and numbers (percentages) were used to describe categorical variables. Association between categorical variables, including study group (mild flu vs. flu-negatives), rs12252 genotype (CC, CT, TT, and C carriers), rs 12252 allele (C and $\mathrm{T})$, province (Markazi, Semnan, and Zanjan), diabetes (positive vs. negative), and hypercholesterolemia (positive vs. negative), was assessed using Pearson's chi-squared test. For each cell with zero counts in contingency tables, Yates's correction was used. Also, where more than $20 \%$ of cells had counts less than 5, the alternative Fisher's exact test was used instead of Pearson's chi-squared test. Univariable logistic regression was used to test the association of each independent variable with mild flu. Variables with a $P$ value smaller than 0.2 in the univariable model were included into the multivariable logistic regression. Also, a backward method using likelihood ratio tests (LRT) was used to make the model as simple as possible. As we sampled cases and controls from three distinct provinces of Iran, we retained the variable "province" in the final model. This was to ensure that residual population admixture, due to differences in participants' area of residence, does not confound the association between rs12252 genotypes and mild flu. All statistical tests were two-tailed with a type I error of 0.05 . Observed powers of the estimated crude and adjusted odds ratios (OR) were also calculated to assess the robustness of our results (Additional file 1).

\section{Results \\ Participants}

A total of 79 mild flu cases and 125 controls were included in this study. Participants' mean age in the case and control groups was 46.46 (SD: 22.90) and 50.62

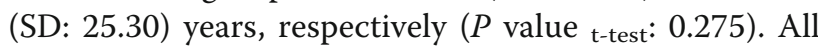
participants were of Fars ethnicity, which is the dominant ethnicity in Iran. The distribution pattern of flupositive and flu-negative individuals was similar across three provinces, with Semnan having the highest number of both cases $(45.57 \%)$ and controls $(72.80 \%)$, and Zanjan having the lowest number of cases $(12.66 \%)$ and controls $(7.20 \%)$. The difference in the number of cases and controls was significant between Semnan and

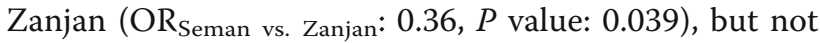
between Semanan and Markazi or between Zanjan and Markazi provinces. Details of participants' characteristics are shown in Table 2.

\section{Anthropometric and clinical characteristics of study participants}

The mean BMI value was slightly higher among mild flu patients rather than in controls $(P$ value: 0.034$)$. Prevalence of hypercholesterolemia and diabetes was also significantly higher in controls rather than in mild flu patients ( $P$ values: 0.042 and 0.005 , respectively; Table 2 ).

\section{Genotyping and genetic analysis}

The TT genotype was the most prevalent genotype both among cases (84.81\%) and controls (96.00\%). Similarly, the CC genotype was the least prevalent genotype in both groups (cases: $3.80 \%$, controls: $0.80 \%$, Table 2 ). In both 
Table 2 Participants' characteristics and univariable logistic regression of the association between mild flu and rs 12252 polymorphisms, BMI, diabetes, and hypercholesterolemia in an Iranian sample with Fars ethnic background

\begin{tabular}{|c|c|c|c|c|c|}
\hline \multirow[t]{2}{*}{ Variables } & \multirow{2}{*}{$\begin{array}{l}\text { Case } \\
n=79\end{array}$} & \multirow{2}{*}{$\begin{array}{l}\text { Control } \\
n=125\end{array}$} & \multirow[t]{2}{*}{ OR } & \multirow[t]{2}{*}{$95 \% \mathrm{Cl}$} & \multirow[t]{2}{*}{$P$ value } \\
\hline & & & & & \\
\hline Age $_{(\text {mean } \pm S D)}$ & $46.46 \pm 22.90$ & $50.62 \pm 25.30$ & 0.99 & $0.98,1.00$ & 0.275 \\
\hline $\mathrm{BMI}_{(\text {mean } \pm \mathrm{SD})}$ & $26.51 \pm 8.67$ & $23.76 \pm 4.67$ & 1.06 & $1.01,1.13$ & 0.034 \\
\hline \multicolumn{6}{|l|}{ Province $\mathrm{n}(\%)$} \\
\hline Semnan & $36(45.57)$ & $91(72.80)$ & 0.36 & $0.13,0.95$ & 0.039 \\
\hline Markazi & $33(41.77)$ & $25(20.00)$ & 1.19 & $0.42,3.36$ & 0.745 \\
\hline Zanjan & $10(12.66)$ & $9(7.20)$ & 1 & - & - \\
\hline \multicolumn{6}{|c|}{ Hypercholesterolemia n (\%) } \\
\hline Positive & $3(3.80)$ & $16(12.80)$ & 0.27 & $0.08,0.96$ & 0.042 \\
\hline Negative & $76(96.20)$ & $109(87.20)$ & 1 & - & - \\
\hline \multicolumn{6}{|l|}{ Diabetes n (\%) } \\
\hline Positive & $12(15.19)$ & $42(33.60)$ & 0.35 & $0.17,0.73$ & 0.005 \\
\hline Negative & $67(84.81)$ & $83(66.40)$ & 1 & - & - \\
\hline \multicolumn{6}{|l|}{ Genotype n (\%) } \\
\hline CC & $3(3.80)$ & $1(0.80)$ & 5.37 & $0.55,52.68$ & 0.149 \\
\hline $\mathrm{TC}$ & $9(11.39)$ & $4(3.20)$ & 4.03 & $1.20,13.58$ & 0.025 \\
\hline$C C+C T$ & $12(15.19)$ & $5(4.00)$ & 4.29 & $1.45,12.72$ & 0.008 \\
\hline$\pi$ & $67(84.81)$ & $120(96.00)$ & 1 & - & - \\
\hline \multicolumn{6}{|l|}{ Allele n (\%) } \\
\hline C allele & 15 (9.49) & $6(2.40)$ & 4.26 & $1.51,13.67$ & 0.0016 \\
\hline T allele & $143(90.51)$ & $244(97.60)$ & 1 & - & - \\
\hline
\end{tabular}

groups, the alleles were in HWE ( $P$ value $>0.05$, Table 3 ). The distribution of TT, TC, CC genotypes as well as C carriers was not significantly different across three provinces, either in total, or separately among cases and controls (Table 3).

\section{Association of rs 12252 polymorphisms, BMl, diabetes, and hypercholesterolemia with mild flu}

Results of the univariable logistic regression showed that having TC genotype rather than TT, significantly increased the risk of mild flu (OR: 4.03, $P$ value: 0.025 ). The same effect, but with greater magnitude, was also observed for the CC genotype rather than the TT genotype, however, this effect was not statistically significant (OR: 5.37, $P$ value: 0.149 ; Table 2 ). In the final model, the effect of both TC and CC genotypes on the risk of mild flu showed an increase, but again this effect was only significant in the TC group. Furthermore, carriers of the rs12252 C allele (CT + CC genotypes) showed 5.92 folds increase in the risk of mild flu comparing to the $\mathrm{T}$ allele homozygotes ( $P$ value: 0.007$)$. In the final model, the effect of BMI, diabetes, and hypercholesterolemia were no longer statistically significant (Table 4).
Table 3 IFITM3 rs12252 genotype frequencies among mild flu cases and flu-negative controls, based on participants' province of residence

\begin{tabular}{|c|c|c|c|c|c|c|c|}
\hline & \multicolumn{3}{|c|}{ Genotype } & \multirow[b]{2}{*}{$P$ value ${ }^{a *}$} & \multirow[b]{2}{*}{$P$ value ${ }^{b *}$} & \multicolumn{2}{|l|}{ HWE } \\
\hline & CC & $\mathrm{TC}$ & $\pi$ & & & $x^{2}$ & $P$ value \\
\hline Total & & & & 0.120 & 0.926 & - & - \\
\hline \multicolumn{8}{|l|}{ Province } \\
\hline Zanjan & 0 & 1 & 18 & & & & \\
\hline Semnan & 1 & 11 & 115 & & & & \\
\hline Markazi & 3 & 1 & 54 & & & & \\
\hline Cases & & & & & & 0.63 & $>0.05$ \\
\hline Province & & & & 0.073 & 0.099 & - & - \\
\hline Zanjan & 0 & 0 & 10 & & & & \\
\hline Semnan & 1 & 8 & 27 & & & & \\
\hline Markazi & 2 & 1 & 30 & & & & \\
\hline Controls & & & & & & 0.03 & $>0.05$ \\
\hline Province & & & & 0.185 & 0.361 & - & - \\
\hline Zanjan & 0 & 1 & 8 & & & & \\
\hline Semnan & 0 & 3 & 88 & & & & \\
\hline Markazi & 1 & 0 & 24 & & & & \\
\hline $\begin{array}{l}\text { HWE Hardy Wei } \\
\text { *Fisher's exact } t \\
\text { aAssociation an } \\
\text { TC, and TT) } \\
\text { b Association an } \\
\text { (CT + CC vs. T) }\end{array}$ & $\begin{array}{l}\text { berg } \\
\text { st } \\
\text { lyses }\end{array}$ & $\begin{array}{l}\text { Equilit } \\
\text { are pe }\end{array}$ & $\begin{array}{l}\text { rium } \\
\text { forme }\end{array}$ & based on co & dominant ge & netic $m$ & del (CC, \\
\hline
\end{tabular}

Details of multivariable regression process are presented in Additional file 2.

\section{Discussion}

Advances in the genomic area have enlightened the role of genetic factors in susceptibility to various infectious diseases. In this regard, IFITM3 protein encoded by IFITM gene, have shown to be associated with susceptibility to several viral infections, such as West Nile virus, dengue virus, rhinovirus, corona virus, HIV, respiratory syncytial virus, and influenza A virus [3, 15, 20, 28]. In case of influenza infection, however, it is not clear whether the reported association relates to the infection severity.

Table 4 Multivariable logistic regression of the association between IFITM3 rs12252 polymorphisms and mild flu in an Iranian sample with Fars ethnic background

\begin{tabular}{llll}
\hline Genotype & $\mathrm{OR}^{\mathrm{a}}$ & $95 \% \mathrm{Cl}$ & $P$ value \\
\hline $\mathrm{CC}$ & 2.71 & $0.26,28.57$ & 0.406 \\
$\mathrm{CT}$ & 7.62 & $1.69,34.39$ & 0.008 \\
$\mathrm{CC}+\mathrm{CT}$ & 5.92 & $1.59,22.09$ & 0.007 \\
$\pi$ & 1 & - & - \\
\hline
\end{tabular}

${ }^{\mathrm{a} O R s}$ are adjusted for $\mathrm{BMI}$ and province of residence 
In this study, we investigated the association between mild flu and IFITM3 rs12252 variant, BMI, diabetes, and hypercholesterolemia in an Iranian population. Our results suggest a significant positive association between mild flu and rs12252 $\mathrm{C}$ allele heterozygous $(\mathrm{CT})$ and carriage $(\mathrm{CT}+\mathrm{CC})$, but not between mild flu and $\mathrm{C}$ allele homozygous (CC), BMI, diabetes, and hypercholesterolemia.

IFITM/ IFITM3 proteins are membrane-associated proteins, and directly interfere with the virus entry into the host's cells [20]. Since virus entry often proceeds through endocytosis, it is possible that IFITM proteins are involved in endocytosis, by detecting and eliminating viral invaders before establishment of infection [3, 21]. Therefore, mutation in the gene coding for these proteins can lead to susceptibility to various infections. Yount, et al. (2010) introduced IFITM3 in mouse dendritic cells. They mentioned S-palmitoylation of IFITM3 on proximal cysteines controls its clustering in membrane compartments and its antiviral activity against influenza virus. [30]. Bailey and colleagues also found that IAV lung titers were higher in Ifitm3 knockout mice versus wild-type animals [2].

The association of IFITM gene polymorphisms with mild and sever influenza has been investigated in different ethnicities. For example, Zhang, et al. pointed to the significant role of IFITM3 genetic variants on the epidemiology of influenza among Chinese individuals [31]. Yang, et al. found a significant association between IFITM3-SNP rs12252 and susceptibility to severe, but not mild flu, among Asian and Caucasian ethnicities [29]. Conversely, Mills, et al. found evidence of an association between rs12252 C allele homozygotes and susceptibility to mild flu in patients with Caucasian ancestry, attending primary care, but could not confirm the association between this SNP and susceptibility to severe flu [22]. Studies conducted by López-Rodríguez and Giao, et al. did not find evidence for the association between rs12252 C allele homozygotes and susceptibility to sever flu $[11,19,22]$.

Based on the conclusion from the review paper of Ciancanelli et al. which mentioned IFITM3 SNP could not be a major causal factor, but perhaps a modifier, of the outcome of influenza infection [6], we also concluded there is only convincing experimental evidence for the role of wild-type IFITM3 but further work is required to define the role of IFITM3 SNPs as modifiers for severe influenza. The inconsistent results reported by studies investigated the association between IFITM3 SNP rs12252 and influenza, made Yang, et al. to conduct a systematic review. Their meta-analysis included 445 patients with influenza and 4180 controls from four studies, including different ethnic and severity subgroups. Their results showed that patients with the
rs12252-C/C genotype were more likely to increase the susceptibility to severe but not in mild flu, in both UK Caucasians and Han Chinese [29].

Our results also showed that rs12252-C carriers have an increased risk of mild flu rather than patients with TT genotype. This may be explained as due to the differences in participants' ethnic background, since we studied Iranian ethnicities while Yang, et al. focused on UK Caucasians and Han Chinese ethnicities. Although, the rs12252-C allele in the Iranian population was rare, the overall effect of this allele on the risk of influenza was found to be considerably high. As our sample size was small, the power for some of our estimates was not desirable. In case such findings being replicated by future studies, the knowledge can be used in effective management of the epidemics. For example, understanding the biological pathways leading to mild and severe flu may lead to improvement of therapeutic options, and can alter existing vaccination practices. Findings of largescale studies on genetic susceptibility to influenza would also guide population-based prevention efforts. For example, by considering the genetic susceptibility of different sub-populations to influenza virus in a country, human and medical resources would be allocated to high risk areas in case epidemics/pandemics occur.

The IFITM3 allele frequency varies significantly among different ethnicities. For example, the frequency of rs12252 C allele homozygotes in Han Chinese, Japanese, Northern Europeans, and Englanders has been shown to vary greatly, from $0 \%$ among Japanese to $44 \%$ among Chinese populations $(25,44,0$ and $2 \%$, respectively) [16]. Little is known about the frequency of this genotype in Iran. In our study, the $\mathrm{C}$ allele frequency observed among flu-negative individuals was $2.40 \%$, resembling the allele frequency among Englanders. Studies with larger sample sizes would provide a better understanding about the frequency of susceptibility alleles in Iran.

In this study, we recruited our samples from three provinces of Northern-Central Iran, including Markazi, Semnan, and Zanjan provinces. Although all participants were of Iranian ethnicity, participants of each province might be different regarding their genetic and social history, leading to residual confounding due to population stratification. Population stratification is related to situations when cases and controls are of different ethnic backgrounds with different genetic compositions, and has been noted as the most important type of the bias in genetic association studies. To control for the effect of residual population admixture on our results, we adjusted genetic association between IFITM3-SNP rs12252 and susceptibility to mild flu for participants' residence area. Growing empirical and theoretical evidence suggests that statistical adjustment for confounding effect of 
ethnicity provides estimates of genetic associations which are robust to bias from population stratification [4].

In our study, we did not observe a significant association between rs12252 $\mathrm{C}$ allele homozygote, $\mathrm{BMI}$, diabetes, and hypercholesterolemia and mild flu. This might be due to relatively small sample size in our study, which led to moderate power of some parameter estimates. To verify these findings, further studies on the Iranian ethnicity with larger sample sizes are recommended.

\section{Conclusions}

To the best of our knowledge, this is the first study evaluating the association between IFITM3 rs12252 polymorphism, diabetes, hypercholesterolemia and BMI with susceptibility to mild flu in an Iranian sample. Our results suggest a significant positive association between mild flu and rs12252 $\mathrm{C}$ allele heterozygous and carriage. However, we did not observe an association between mild flu and rs12252 $\mathrm{C}$ allele homozygous, BMI, diabetes, and hypercholesterolemia. Further studies are recommended to verify these findings in a larger sample of Iranian individuals. Future replication of the strong association observed here between rs12252 C allele carriage and mild flu would be beneficial in candidating this polymorphism as a genetic marker for early screening of susceptibility to mild flu.

\section{Additional files}

Additional file 1: Multivariable logistic regression of the association between IFITM3 rs12252 polymorphisms and mild flu in an Iranian sample with Fars ethnic background: Intermediate results. (DOCX 16 kb)

Additional file 2: Univariable and multivariable logistic regression of the association between mild flu and IFITM3 rs 12252 polymorphisms, BML diabetes, and hypercholesterolemia in an Iranian sample with Fars ethnic background: observed powers. (DOCX $20 \mathrm{~kb}$ )

\section{Abbreviations}

IAV: Influenza A virus; IFITM: Interferon-inducible transmembrane; ISGs: Interferon stimulated genes; PRRs: Pathogen recognition receptors; qRT-PCR: Quantitative real-time PCR; SARS: Severe acute respiratory syndrome; WHO: World Health Organization

\section{Acknowledgements \\ The authors would like to thank Dr. Amin Doosti Irani for his valuable consultation in statistical analysis.}

\section{Funding}

This study was funded by National Elites Foundation, Iran (grant number 831).

Availability of data and materials

All data in case of need are available.

\section{Authors' contributions}

Conceived and designed the experiments: BF and PM; performed the experiments: PM, HSh, and VM; Analyzed the data: SE, PM, and VM; Contributed reagents/materials/analysis tools: FF and BF; Wrote the paper: PM and SE; Comprehensive reading the manuscript: all authors. All authors read and approved the final manuscript.

\section{Ethics approval}

Clinical investigation was conducted according to the principles expressed in the Declaration of Pasteur Institute of IRAN. This research was reviewed and approved by the Ethics Committee of Pasteur Institute of IRAN (Protocol Number IR.PII.REC.1395.3).

\section{Consent for publication}

Written informed consent was obtained from the patients or the guardians of the patients participated in this research.

\section{Competing interests}

Authors (Parvaneh Mehrbod, Sana Eybpoosh, Fatemeh Fotouhi, Hadis Shokouhi, Vahideh Mazaheri, Behrokh Farahmand) declare that they have no conflicts of interest.

\section{Publisher's Note}

Springer Nature remains neutral with regard to jurisdictional claims in published maps and institutional affiliations.

\section{Author details}

${ }^{1}$ Influenza and Other Respiratory Viruses Department, Pasteur Institute of Iran, Tehran, Iran. ${ }^{2}$ Department of Epidemiology and Biostatistics, Research Centre for Emerging and Reemerging Infectious Diseases, Pasteur Institute of Iran, Tehran, Iran

Received: 26 January 2017 Accepted: 31 October 2017 Published online: 09 November 2017

\section{References}

1. Amini-Bavil-Olyaee S, Choi YJ, Lee JH, Shi M, Huang IC, Farzan M, Jung JU. The antiviral effector IFITM3 disrupts intracellular cholesterol homeostasis to block viral entry. Cell Host Microbe. 2013;13:452-64.

2. Bailey CC, Huang IC, Kam C, Farzan M. IFITM3 limits the severity of acute influenza in mice. PLoS Pathog. 2012:8:e1002909.

3. Brass AL, Huang IC, Benita Y, John SP, Krishnan MN, Feeley EM, Ryan B, Weyer JL, van der Weyden L, Fikrig E, et al. IFITM proteins mediate the innate immune response to influenza a H1N1 virus, West Nile virus and dengue virus. Cell. 2009;139:1243-54.

4. Cardon LR, Palmer LJ. Population stratification and spurious allelic association. Lancet. 2003:361:598-604

5. Chutiwitoonchai N, Hiyoshi M, Hiyoshi-Yoshidomi Y, Hashimoto M, Tokunaga K, Suzu S. Characteristics of IFITM, the newly identified IFNinducible anti-HIV-1 family proteins. Microbes Infect. 2013;15:280-90.

6. Ciancanelli MJ, Abel L, Zhang SY, Casanova JL. Host genetics of severe influenza: from mouse Mx1 to human IRF7. Curr Opin Immunol. 2016:38:109-20.

7. Compton AA, Roy N, Porrot F, Billet A, Casartelli N, Yount JS, Liang C, Schwartz O. Natural mutations in IFITM3 modulate post-translational regulation and toggle antiviral specificity. EMBO Rep. 2016;17:1657-71.

8. Cui Q, Ju X, Yang T, Zhang M, Tang W, Chen Q, Hu Y, Haas JV, Troutt JS, Pickard RT, et al. Serum PCSK9 is associated with multiple metabolic factors in a large Han Chinese population. Atherosclerosis. 2010;213:632-6.

9. Everitt AR, Clare S, Pertel T, John SP, Wash RS, Smith SE, Chin CR, Feeley EM, Sims JS, Adams DJ, et al. IFITM3 restricts the morbidity and mortality associated with influenza. Nature. 2012;484:519-23.

10. Feeley EM, Sims JS, John SP, Chin CR, Pertel T. Chen L-i, Gaiha GD, Ryan BJ, Donis RO, Elledge SJ, et al. IFITM3 inhibits influenza a virus infection by preventing cytosolic entry. PLoS Pathog. 2011;7:e1002337.

11. Gaio V, Nunes B, Pechirra P, Conde P, Guiomar R, Dias CM, Barreto M. Hospitalization risk due to respiratory illness associated with genetic variation at IFITM3 in patients with influenza a(H1N1)pdm09 infection: a case-control study. PLoS One. 2016;11:e0158181.

12. He J, Gu D, Wu X, Reynolds K, Duan X, Yao C, Wang J, Chen CS, Chen J, Wildman RP, et al. Major causes of death among men and women in China. New Engl J Med. 2005;353:1124-34.

13. Horby P, Nguyen NY, Dunstan SJ, Baillie JK. The role of host genetics in susceptibility to influenza: a systematic review. PLoS One. 2012;7:e33180.

14. Huang IC, Bailey CC, Weyer JL, Radoshitzky SR, Becker MM, Chiang JJ, Brass AL, Ahmed AA, Chi X, Dong L, et al. Distinct patterns of IFITM-mediated restriction of filoviruses, SARS coronavirus, and influenza a virus. PLoS Pathog. 2011;7:e1001258. 
15. Jiang D, Weidner JM, Qing M, Pan XB, Guo H, Xu C, Zhang X, Birk A, Chang $J$, Shi PY, et al. Identification of five interferon-induced cellular proteins that inhibit West Nile virus and dengue virus infections. J Virol. 2010;84:8332-41.

16. Kiselev OI, Komissarov AB, Konshina OS, Dmitrieva MN, Deyeva EG, Sologub TV, Pokrovskiy VI. Mutations in human genes that increase the risk for severe influenza infection microb independent. Res J. 2015;2:10-8.

17. Konig R, Stertz S, Zhou Y, Inoue A, Hoffmann HH, Bhattacharyya S, Alamares JG, Tscherne DM, Ortigoza MB, Liang Y, et al. Human host factors required for influenza virus replication. Nature. 2010;463:813-7.

18. Lander ES. Initial impact of the sequencing of the human genome. Nature. 2011:470:187-97.

19. López-Rodríguez M, Herrera-Ramos E, Solé-Violán J, Ruíz-Hernández JJ, Borderías L, Horcajada JP, Lerma-Chippirraz E, Rajas O, Briones M, PérezGonzález MC, et al. IFITM3 and severe influenza virus infection. No evidence of genetic association. Eur J Clin Microbiol Infect Dis. 2016:35:1811-7.

20. Lu J, Pan Q, Rong L, He W, Liu SL, Liang C. The IFITM proteins inhibit HIV-1 infection. J Virol. 2011;85:2126-37.

21. Mercer J, Schelhaas M, Helenius A. Virus entry by endocytosis. Annu Rev Biochem. 2010;79:803-33.

22. Mills T, Rautanen A, Elliott KS, Parks T, Naranbhai V, leven MM, Butler CC, Little P, Verheij T, Garrard CS, et al. IFITM3 and susceptibility to respiratory viral infections in the community. J Infect Dis. 2014;209:1028-31.

23. Niu N, Zhu X, Liu Y, Du T, Wang X, Chen D, Sun B, Gu HF, Liu Y. Single nucleotide polymorphisms in the proximal promoter region of apolipoprotein M gene (apoM) confer the susceptibility to development of type 2 diabetes in Han Chinese. Diabetes Metab Res Rev. 2007;23:21-5.

24. Rodriguez S, Gaunt TR, Day INM. Hardy-weinberg equilibrium testing of biological ascertainment for mendelian randomization studies. Am J Epidemiol. 2009;169:505-14.

25. Sadler AJ, Williams BRG. Interferon-inducible antiviral effectors. Nature Rev Immunol. 2008:8:559-68.

26. Schoggins JW, Wilson SJ, Panis M, Murphy MY, Jones $C T$, Bieniasz P, Rice $\mathrm{CM}$. A diverse range of gene products are effectors of the type I interferon antiviral response. Nature. 2011;472:481-5.

27. Wang Z, Zhang A, Wan Y, Liu X, Qiu C, Xi X, Ren Y, Wang J, Dong Y, Bao M, et al. Early hypercytokinemia is associated with interferon-induced transmembrane protein-3 dysfunction and predictive of fatal H7N9 infection. P Natl Acad Sci USA. 2014;111:769-74.

28. Weidner JM, Jiang D, Pan XB, Chang J, Block TM, Guo JT. Interferon-induced cell membrane proteins, IFITM3 and Tetherin, inhibit vesicular stomatitis virus infection via distinct mechanisms. J Virol. 2010;84:12646-57.

29. Yang X, Tan B, Zhou X, Xue J, Zhang X, Wang P, Shao C, Li Y, Li C, Xia H, et al. Interferon-inducible Transmembrane protein 3 genetic variant rs 12252 and influenza susceptibility and severity: a meta-analysis. PLoS One. 2015;10: e0124985.

30. Yount JS, Moltedo B, Yang Y-Y, Charron G, Moran TM, López CB, Hang HC. Palmitoylome profiling reveals S-palmitoylation-dependent antiviral activity of IFITM3. Nat Chem Biol. 2010;6:610-4.

31. Zhang YH, Zhao Y, Li N, Peng YC, Giannoulatou E, Jin RH, Yan HP, Wu H, Liu $\mathrm{JH}$, Liu N, et al. Interferon-induced transmembrane protein-3 genetic variant rs12252-C is associated with severe influenza in Chinese individuals. Nat Commun. 2013;4:1418

\section{Submit your next manuscript to BioMed Central and we will help you at every step:}

- We accept pre-submission inquiries

- Our selector tool helps you to find the most relevant journal

- We provide round the clock customer support

- Convenient online submission

- Thorough peer review

- Inclusion in PubMed and all major indexing services

- Maximum visibility for your research

Submit your manuscript at www.biomedcentral.com/submit

) Biomed Central 